\title{
The contribution of obesity to carotid atherosclerotic plaque burden in a general population sample in Norway: The Tromsø Study
}

Yume Imahori ${ }^{\mathrm{a}, \#}$, Ellisiv B. Mathiesen ${ }^{\mathrm{b}}$, David A. Leon ${ }^{\mathrm{a}, \mathrm{c}}$, Laila A. Hopstock ${ }^{\mathrm{d}}$, Alun D. Hughes ${ }^{\mathrm{f}}$, Stein Harald Johnsen ${ }^{\mathrm{b}}$, Lone Jørgensen ${ }^{\mathrm{d}, \mathrm{e}}$, Nina Emaus ${ }^{\mathrm{d}}$, Katy E. Morgan ${ }^{\mathrm{g}}$

${ }^{a}$ London School of Hygiene \& Tropical Medicine, Department of Non-communicable Disease Epidemiology, Faculty of Epidemiology and Population Health, UK

${ }^{b}$ UiT The Arctic University of Norway, Department of Clinical Medicine, and Department of Neurology, University Hospital of North Norway, Norway

'UiT The Arctic University of Norway, Department of Community Medicine, Faculty of Health Sciences, Norway

${ }^{\mathrm{d} U i T}$ The Arctic University of Norway, Department of Health and Care Sciences, Faculty of Health Sciences, Norway

eUiT The Arctic University of Norway, Department of Clinical Therapeutic Services, University Hospital of North Norway, Troms $\emptyset$, Norway

${ }^{\mathrm{f}}$ University College London, Department of Population Science \& Experimental Medicine, UCL Institute of Cardiovascular Science, Faculty of Population Health Sciences, UK

'London School of Hygiene \& Tropical Medicine, Department of Medical Statistics, Faculty of Epidemiology and Population Health, UK

\# Corresponding author: Yume Imahori, London School of Hygiene and Tropical Medicine, Keppel Street London WC1E 7HT, UK

Email address: yume.imahori@1shtm.ac.uk

Word counts: abstract 250 words, main text 3712 words (word limits: abstract 250 words, main text 4000 words) 4 tables 


\section{Abstract (250 words)}

Background: Few studies have investigated the association of different measures of adiposity with carotid plaque.

Aims: To investigate and compare the associations of four measures of adiposity: body mass index (BMI), waist circumference (WC), waist-to-hip ratio (WHR), and waist-to-height ratio (WHtR) with the presence of carotid plaque and total plaque area (TPA) in the right carotid artery.

Methods: We included 4906 individuals aged 31-88 years who participated in a population-based study with ultrasonography of the right carotid artery. Adiposity measures were converted to sexspecific SD units to allow comparison of effect sizes. TPA was log transformed due to its skewed distribution. Logistic and linear regression models were used respectively to investigate the association of each adiposity measure with the presence of plaque and with log-transformed TPA. Estimates were adjusted for potential confounders and mediators such as blood pressure and lipids.

Results: After adjustment for age, sex, smoking, and education level, there was strong evidence of an association between all adiposity measures and log-transformed TPA, whereas only WHR was weakly associated with presence of plaque. WHR showed the largest adjusted effect size for both logtransformed TPA (beta 0.055, 95\%CI 0.028-0.081) and the presence of plaque (OR 1.07, 95\%CI 1.011.15). Adjustment for mediators led to appreciable attenuation of observed effects.

Conclusions: Adiposity is more consistently associated with extent of plaque burden than with whether an individual does or does not have any plaque. There was evidence that established biomarkers mediate much of this association. Abdominal adiposity appears to show the strongest effect.

Key words: Atherosclerosis, carotid plaque, adiposity, anthropometric measures, waist-to-hip ratio (WHR) 


\section{Introduction}

Obesity is a global epidemic, affecting an increasing proportion of the world's population (1). In 2014, approximately $40 \%$ of adults worldwide were estimated to be overweight, and $13 \%$ obese (2). This trend is alarming because it might be expected to result in a steep increase in non-communicable diseases, particularly cardiovascular disease (CVD) which is the leading cause of death worldwide. Obesity contributes to CVD through a variety of pathways including hypertension, hyperlipidemia, and diabetes (3). A better understanding of the pathways through which obesity affects CVD risk may contribute to developing interventions to mitigate the effect of this modifiable risk. Furthermore, it is known that to achieve sufficient weight-loss and to sustain it for a long-term is relatively difficult while the control of hypertension, hyperlipidemia, and diabetes are well-established $(4,5)$.

Many studies have investigated the association between various adiposity measures and subclinical carotid atherosclerosis (6). However, most of these have focussed on carotid intima-media thickness (IMT). Studies using carotid plaque as an outcome are scarce, and most of them use the binary indicator of presence or absence of plaque (7-15). Although studies have consistently shown that increased IMT predicts future CVD events, increased IMT does not necessarily reflect atherosclerotic changes of the carotid artery and can be caused by other mechanisms (16). In contrast, the presence of carotid plaque is characteristic of a later stage of atherosclerosis and thus, not surprisingly, predicts future CVD events better than IMT (17). Beyond this, a quantitative measure of carotid plaque burden, such as total plaque area (TPA), has also been shown to be strongly predictive of future CVD events $(18,19)$.

A small number of studies have investigated the association of body mass index (BMI) with quantitative measures of carotid plaque burden, although they failed to demonstrate a significant association $(13,20)$. However, BMI has limitations as a measure of adiposity $(21)$. It neither differentiates between fat and lean mass nor does it reflect body fat distribution. Accumulating evidence suggests that abdominal obesity may be correlated with CVD risks more strongly than general obesity, reflecting a more important role of visceral adipose tissues in the development of CVD (22). Waist circumference (WC), waist-to-hip ratio (WHR), and waist-to-height ratio (WHtR) are easily evaluated in a routine clinical setting and reflect abdominal obesity better than BMI. To our knowledge, associations of plaque burden with these alternative measures of adiposity have not been investigated.

The aim of our study was to evaluate the associations between four adiposity measures (BMI, WC, WHR, WHtR) and plaque presence (yes/no) as well as TPA in a population-based sample. In addition, we investigated the extent to which established CVD risk factors mediated any such associations. We used the Norwegian Troms $\emptyset$ Study which is one of few population-based studies that have quantitative plaque measures as well as multiple measures of adiposity. 


\section{Materials and Methods}

\section{Participants}

Subjects in this analysis participated in the fifth survey of the Troms $\varnothing$ Study (Troms $\varnothing 5$ ) conducted in 2001-02. The Tromsø Study is a large population-based study with repeated health surveys conducted in the municipality of Troms $\varnothing$, Norway, which started in 1974. Details of the Troms $\varnothing$ Study have been published previously (23).

The study consisted of two parts: a first visit that collected data via questionnaires, interviews, physical examinations and biological samples, and a second visit at which more extensive clinical examinations were conducted, including carotid ultrasonography. A total of 10353 people aged 30-89 years were invited to the first visit, and 8130 people attended (23). A subset of 6969 participants among those who attended the first visit were invited to the second visit, of whom 5952 attended. The Regional Committee for Research Ethics approved the study, and The Norwegian Data Inspectorate licensed the data.

\section{First visit measurements}

Height, weight, waist and hip circumference were measured using standard methods. Blood pressure was measured using Dinamap Vital Signs Monitor 18461. After a 2-minute rest, three measurements were taken with one-minute intervals, with the participant in a sitting position. The mean of the two final readings was used in the analysis. Smoking habit, length of education (years), and medical history (hypertension, diabetes, CVD) were collected from self-administered questionnaires. A nonfasting blood sample was obtained. Serum total cholesterol and triglycerides were analyzed with enzymatic colorimetric methods. Serum high-density lipoprotein (HDL) cholesterol was measured after separating apoB containing lipoproteins by using heparin and manganese chloride (24). Lowdensity lipoprotein (LDL) cholesterol was calculated using the Friedewald equation.

\section{Ultrasound examination}

By design, the carotid plaque examinations excluded those who had not had a carotid ultrasound examination in the Troms $\varnothing 4$ study (1994-95). This meant that of those who attended the second visit $(\mathrm{N}=5952)$, carotid ultrasound examinations in Troms $\varnothing 5$ were conducted on only 5453 participants, of whom data was available for analysis for 5423 .

Carotid plaque was assessed by recording ultrasonographic images of the right carotid artery using an Acuson Xp10 128 ART ultrasound scanner equipped with a linear array 5-7 MHz transducer. Participants were in a supine position during the examination. 
The plaque was defined as a localized protrusion of the vessel wall into the lumen of at least $50 \%$ compared with the adjacent intima-media thickness. The near and far wall of the common carotid artery, bifurcation, and internal carotid artery were examined to seek plaques, and a score was calculated based on the presence of plaque in each location up to a maximum of six. For each plaque identified, a longitudinal still plaque image was recorded. Subsequent offline reading was undertaken to measure plaque area using a semi-automatic border detection software Arterial Measurement System (AMS) that involved the operator outlining each plaque (25). For those with more than one plaque, all plaque areas were added together to calculate TPA. Details of the ultrasound examination have been described in a previous publication (26).

\section{Statistical methods}

Characteristics of the study population were summarised using means with standard deviations (SD) or medians with the inter-quartile range for continuous variables, or numbers and percentages for categorical variables.

The distribution of TPA was highly skewed and zero-inflated (Figure 1), which led us to use a combination of two models. A logistic regression model was used with presence of plaque (yes/no) as an outcome to explore the association of adiposity with having at least one plaque. Secondly, logtransformed TPA was used as the outcome in a linear regression model to explore the association between adiposity and plaque burden excluding those with no recorded plaque. TPA was logtransformed to improve the approximation to the normal distribution. These two models in conjunction are equivalent to using a hurdle model (27), with the logistic regression modelling the distribution of zero plaque versus at least one plaque, and the linear regression modelling the distribution of the non-zero measures.

For both outcomes, we investigated the association with four different measures of adiposity: BMI, WC, WHR, WHtR. To directly compare the strength of association of each adiposity measure, taking account of the different distributions in men and women, we calculated sex-specific standardized adiposity scores-by subtracting the sex-specific mean of each adiposity measure from the observed value and then dividing by the sex-specific SDs. We fitted a sequence of three models to each of the adiposity measures in turn. Model 1 was adjusted for age as a continuous variable and sex. Model 2 was further adjusted for potential behavioural confounders; smoking (a categorical variable of three levels: current smoker, ex-smoker, never-smoker), and years of education (as a continuous variable). Model 3 was additionally adjusted for potential biological mediators of the association between adiposity and plaque as follows; systolic blood pressure (SBP), HDL-cholesterol, LDL-cholesterol and glycated hemoglobin (HbA1c), all as continuous variables. These analyses were restricted to participants with all four adiposity measures and all covariates recorded to compare effect sizes. 
Previous research on adiposity in relation to cIMT has suggested that there may be different associations seen in men and women (28). We therefore checked for interactions with sex in the associations of adiposity with TPA, by adding interaction terms for all three models.

Statistical analyses were performed using Stata statistical software (version 14: Stata Corp) (29).

\section{Results}

Of the 5423 subjects for whom we had carotid ultrasound data, we used the subset of 4906 who had complete data on all relevant variables. Missing data on education (5\%) and HbA1c (2\%) were the main reasons for subjects being dropped from the analyses. The characteristics of the subset analysed were very similar to that of all subjects who had undergone carotid ultrasound examination (data not shown).

The prevalence of carotid plaque and median TPA are shown in Table 1. The prevalence of having at least one plaque was $60 \%$. Table 2 shows the means of each adiposity measure by category of plaque burden. There was a tendency for the adiposity means to increase across categories of plaque burden except for BMI.

Table 3 shows the odds ratios for the presence of plaque for each of the four adiposity measures. In models 1 and 2 only WHR showed some evidence of an association with presence of plaque. This was attenuated and became non-significant on adjustment for mediators in model 3 .

Table 4 shows the associations of log-TPA with each adiposity measure. There was evidence of positive associations with all four measures in model 2 after adjustment for potential confounders, with WHR showing the strongest effect. All associations were attenuated on further adjustment for potential mediators, with WHR remaining the only one showing (weak) evidence of an association. Tests for interactions between adiposity and sex and adiposity and age on $\log$-TPA were nonsignificant (data not shown).

\section{Discussion}

To our knowledge, this is the first study to investigate the burden of carotid plaque and multiple adiposity measures in a large population-based study. Our study had three major findings. First, all adiposity measures were associated with $\log$-TPA, but the evidence for an association with plaque presence was weak except for WHR. Second, the associations between adiposity and carotid plaque appeared to be at least partially mediated by traditional CVD risk factors. Thirdly, our main measure 
of central obesity (WHR) showed the strongest and most consistent association with plaque presence and burden.

Previous studies investigating the association between adiposity and the presence of plaque are scarce, and the results are inconsistent (7-12) in part reflecting differences in statistical methods and the extent to which adjustments were made separately for potential confounders and mediators.

Czernichow et al. showed that BMI, WC, and WHR were not associated with carotid plaque occurrence after adjustment for traditional CVD risk factors in 1014 healthy adults (9). Several other studies however had results that were broadly consistent with our analyses. A French study with 6265 participants aged 65-years and older showed that frequency of carotid plaque increased as WC and WHR increased, but the association became non-significant after the adjustment for traditional CVD risk factors (10). On the other hand, WHR had significant associations with the presence of plaque in two cross-sectional studies. Chaubey et al. showed that the odds of having plaque increased by approximately $30 \%$ as WHR increased by 0.1 after adjustment for traditional CVD risk factors (8). Finally, an Australian population study showed that those with WHR larger than 0.91 had two-fold increased odds for having plaque compared to those with smaller WHR (11).

The particularly weak association between BMI and the burden of carotid plaque in our analysis after adjustment for traditional CVD risk factors is in line with the only two previous study results $(13,20)$. Herder et al. showed that baseline BMI was not associated with future TPA nor change in TPA in a 13-year follow-up study (13). Selwaness investigated determinants of plaque burden assessed using MRI, and BMI was not significantly associated with the burden of plaque (20). We were unable to find any other studies that had examined plaque burden in relation to any of our three other measures of adiposity.

The fact that our study has found evidence for adiposity being related to extent of plaque burden rather than the presence/absence of plaque per se is intriguing. This may indicate that adiposity contributes to the process of the development of existing plaque more than the process of plaque initiation. However, because TPA is a continuous measure and contains more information than the binary plaque (present/absent) variable this may make an association easier to detect.

Several studies investigated the association between multiple adiposity measures and IMT and compared the effect size. However, their results are inconsistent. After adjustment for traditional CVD risk factors, some studies showed abdominal obesity was more strongly associated with $\operatorname{IMT}(30,31)$ while in one study BMI showed the largest effect size (9). In another study, BMI and WC showed the same effect size (32). It seems which anthropometry measure is the most strongly associated with IMT is still inconclusive.

The potential importance of our finding that TPA is associated with adiposity is underlined by the fact that it has been found to be predictive of CVD events. Spence et al. investigated 1686 patients from an 
atherosclerosis prevention clinic and showed that those in the top TPA quartile had nearly three times the odds of stroke and myocardial infarction compared to those in the first TPA quartile after 5-year follow up (18). The Troms $\varnothing$ Study compared the associations between myocardial infarction and stroke with IMT and TPA. TPA was a strong predictor of future myocardial infarction and stroke, while IMT at the common carotid artery was not associated with future events (19, 34). Sillesen et al. showed that plaque burden was more strongly associated with coronary artery calcium score than IMT (35).

One of our most striking results is that the association of adiposity with the burden of carotid plaque is strongly attenuated by adjustment for biological factors that are plausible mediators of this association. Because our study is cross-sectional it is not possible to describe this as definitive evidence of mediation, but it is consistent with such an interpretation. Looking at the larger literature on mediators of the association between obesity and CVD events, a recent pooled-analysis using 97 cohort studies showed that half of the risk of coronary heart diseases and stroke was mediated by blood pressure, cholesterol, and glucose(36). A more recent report from the ARIC study suggested that the association of obesity with coronary heart disease was fully explained by traditional mediators (37). These results taken overall suggest that strict control of traditional CVD risk factors including lipids and blood pressure could substantially mitigate the harmful effect of obesity on carotid atherosclerosis.

When comparing the effect sizes of four different adiposity measures, WHR showed the largest effect size with a significant association with log-TPA followed by WHtR. While these estimated effects have wide and overlapping confidence intervals and thus any differences need to be treated cautiously, our results do suggest that central (visceral) obesity may play a more important role than obesity as measured by BMI. Visceral adipose tissue is known to pose a greater risk for CVD with its stronger association with insulin resistance and dyslipidemia than total fat and subcutaneous adipose tissue $(38,39)$. It has also been suggested that the visceral adipose tissue contributes to the progress of atherosclerotic change (40).

Our study has some limitations. Firstly, the cross-sectional design does not allow conclusions concerning causality. Secondly, TPA is essentially a 2-dimensional proxy for the volume of a 3dimensional plaque structure. While this may result in measurement error relative to a better assessment of plaque volume, using 3-dimensional ultrasound or MRI for example, this is unlikely to bias the strength of association with plaque size as long as this is a random measurement error in the outcome variable (47). Thirdly, we only had data available for the right carotid artery. However, this is unlikely to have generated bias as there is no reason to believe that the strength of association between adiposity and plaque will differ between right and left carotid. Fourthly, the prevalence of plaque was relatively high in our population. This may be because participants were relatively old and 
the study was conducted in 2001-02 when the CVD event rate in the population was appreciably higher (48). To this extent, whether the strength of association we report here is generalizable to contemporary populations is a matter for further investigation. Finally, a particular strength of our study is that the data are from a large population-based study with a high response rate.

In summary, our results suggest that adiposity measures reflecting abdominal obesity such as WHR may be more closely associated with plaque burden than the traditional measure of BMI, and that these effects may be mediated by established biological risk factors such as blood pressure and lipids. Although further studies are needed to investigate the usefulness of these adiposity measures as predictors for an individual in a clinical setting assessment of these measures may help to identify a high-risk group with advanced carotid plaque. Further research is desirable to investigate the prospective association between adiposity and carotid plaque burden. It has been suggested that TPA could capture the progress of atherosclerosis more sensitively than IMT because longitudinal plaque growth is faster than its growth toward the lumen $(13,51)$. This would make TPA suitable for prospective studies.

\section{Conclusion}

Adiposity is more consistently associated with extent of plaque burden than with whether an individual does or does not have any plaque. Abdominal adiposity appears to show the strongest effects. There was evidence that established biomarkers mediate much of this association. It would be useful to examine the prospective effect of abdominal obesity on the progress of carotid atherosclerosis in a cohort study.

\section{Conflict of interest (mandatory)}

The authors declared they do not have anything to disclose about conflict of interest with respect to this manuscript.

\section{Financial support (if applicable)}

N/A

Author contributions

YI undertook the analyses and drafting of the manuscript. KM advised on statistical methods and analysis. KM, DAL, EM, LAH, and AH provided ongoing guidance during drafting. All authors commented on drafts of the paper and approved the final manuscript. 


\section{References}

1. NCD Risk Factor Collaboration. Trends in adult body-mass index in 200 countries from 1975 to 2014: a pooled analysis of 1698 population-based measurement studies with 19.2 million participants. Lancet. 2016;387(10026):1377-96.

2. World Health Organization. Obesity and overweight 2016 [cited 2017]. Available from: http://www.who.int/mediacentre/factsheets/fs311/en/.

3. Mandviwala T, Khalid U, Deswal A. Obesity and Cardiovascular Disease: a Risk Factor or a Risk Marker? Curr Atheroscler Rep. 2016;18(5):21.

4. Franz MJ, VanWormer JJ, Crain AL, Boucher JL, Histon T, Caplan W, et al. Weight-loss outcomes: a systematic review and meta-analysis of weight-loss clinical trials with a minimum 1-year follow-up. J Am Diet Assoc. 2007;107(10):1755-67.

5. Curioni C, Lourenco P. Long-term weight loss after diet and exercise: a systematic review. International journal of obesity. 2005;29(10):1168.

6. Qu B, Qu T. Causes of changes in carotid intima-media thickness: a literature review. Cardiovasc Ultrasound. 2015;13:46.

7. Bonithon-Kopp C, Touboul PJ, Berr C, Leroux C, Mainard F, Courbon D, et al. Relation of intima-media thickness to atherosclerotic plaques in carotid arteries: The vascular aging (EVA) study. Arteriosclerosis, Thrombosis, and Vascular Biology. 1996;16(2):310-6.

8. Chaubey S, Nitsch D, Altmann D, Ebrahim S. Differing effect of modifiable cardiovascular risk factors on intima-media thickening and plaque formation at different sites of the arterial vasculature. Heart. 2010;96(19):1579-85.

9. Czernichow S, Bertrais S, Oppert JM, Galan P, Blacher J, Ducimetiere P, et al. Body composition and fat repartition in relation to structure and function of large arteries in middle-aged adults (the SU.VI.MAX study). Int J Obes (Lond). 2005;29(7):826-32.

10. Debette S, Leone N, Courbon D, Gariepy J, Tzourio C, Dartigues JF, et al. Calf circumference is inversely associated with carotid plaques. Stroke. 2008;39(11):2958-65.

11. Hung J, McQuillan BM, Nidorf M, Thompson PL, Beilby JP. Angiotensin-converting enzyme gene polymorphism and carotid wall thickening in a community population. Arteriosclerosis, Thrombosis, and Vascular Biology. 1999;19(8):1969-74.

12. Khalil A, Huffman MD, Prabhakaran D, Osmond C, Fall CH, Tandon N, et al. Predictors of carotid intima-media thickness and carotid plaque in young Indian adults: the New Delhi birth cohort. Int J Cardiol. 2013;167(4):1322-8.

13. Herder M, Johnsen SH, Arntzen KA, Mathiesen EB. Risk factors for progression of carotid intima-media thickness and total plaque area: a 13-year follow-up study: the Tromso Study. Stroke. 2012;43(7):1818-23.

14. Bradshaw PJ, Wilkes ET, Thompson PL. Determinants of carotid intima-medial thickness in an urban Australian Aboriginal population. Atherosclerosis. 2007;192(1):218-23.

15. Holewijn S, den Heijer M, van Tits $L$, Swinkels DW, Stalenhoef AF, de Graaf J. Impact of waist circumference versus adiponectin level on subclinical atherosclerosis: a cross-sectional analysis in a sample from the general population. J Intern Med. 2010;267(6):588-98.

16. Den Ruijter HM, Peters SA, Anderson TJ, Britton AR, Dekker JM, Eijkemans MJ, et al. Common carotid intima-media thickness measurements in cardiovascular risk prediction: a metaanalysis. Jama. 2012;308(8):796-803.

17. Inaba Y, Chen JA, Bergmann SR. Carotid plaque, compared with carotid intima-media thickness, more accurately predicts coronary artery disease events: a meta-analysis. Atherosclerosis. 2012;220(1):128-33.

18. Spence JD, Eliasziw M, DiCicco M, Hackam DG, Galil R, Lohmann T. Carotid plaque area: a tool for targeting and evaluating vascular preventive therapy. Stroke. 2002;33(12):2916-22. 
19. Mathiesen EB, Johnsen SH, Wilsgaard T, Bonaa KH, Lochen ML, Njolstad I. Carotid plaque area and intima-media thickness in prediction of first-ever ischemic stroke: a 10-year follow-up of 6584 men and women: the Tromso Study. Stroke. 2011;42(4):972-8.

20. Selwaness $M$, Hameeteman $R$, Van 't Klooster $R$, Van den Bouwhuijsen $Q$, Hofman A, Franco $\mathrm{OH}$, et al. Determinants of carotid atherosclerotic plaque burden in a stroke-free population. Atherosclerosis. 2016;255:186-92.

21. Garvey WT, Mechanick JI, Brett EM, Garber AJ, Hurley DL, Jastreboff AM, et al. AMERICAN ASSOCIATION OF CLINICAL ENDOCRINOLOGISTS AND AMERICAN COLLEGE OF ENDOCRINOLOGY COMPREHENSIVE CLINICAL PRACTICE GUIDELINES FOR MEDICAL CARE OF PATIENTS WITH OBESITY. Endocr Pract. 2016;22 Suppl 3:1-203.

22. Farb MG, Gokce N. Visceral adiposopathy: a vascular perspective. Horm Mol Biol Clin Investig. 2015;21(2):125-36.

23. Jacobsen BK, Eggen AE, Mathiesen EB, Wilsgaard T, Njolstad I. Cohort profile: the Tromso Study. Int J Epidemiol. 2012;41(4):961-7.

24. Johnsen SH, Mathiesen EB, Fosse E, Joakimsen O, Stensland-Bugge E, Njolstad I, et al. Elevated high-density lipoprotein cholesterol levels are protective against plaque progression: a follow-up study of 1952 persons with carotid atherosclerosis the Tromso study. Circulation. 2005;112(4):498-504.

25. Liang $Q$, Wendelhag I, Wikstrand J, Gustavsson T. A multiscale dynamic programming procedure for boundary detection in ultrasonic artery images. IEEE Trans Med Imaging. 2000;19(2):127-42.

26. Fosse E, Johnsen SH, Stensland-Bugge E, Joakimsen O, Mathiesen EB, Arnesen E, et al. Repeated visual and computer-assisted carotid plaque characterization in a longitudinal populationbased ultrasound study: the Tromso study. Ultrasound Med Biol. 2006;32(1):3-11.

27. Mullahy J. specification and testing of some modified count data models. J Econometrics. 1986;33:341-65.

28. Scuteri A, Orru M, Morrell CH, Tarasov K, Schlessinger D, Uda M, et al. Associations of large artery structure and function with adiposity: Effects of age, gender, and hypertension. The SardiNIA Study. Atherosclerosis. 2012;221(1):189-97.

29. StataCorp. Stata Statistical Software: Release 14. College Station, TX: StataCorp LP. 2015.

30. Ge W, Parvez F, Wu F, Islam T, Ahmed A, Shaheen I, et al. Association between anthropometric measures of obesity and subclinical atherosclerosis in Bangladesh. Atherosclerosis. 2014;232(1):234-41.

31. McDonald SP, Maguire GP, Duarte N, Wang XL, Hoy WE. Carotid intima-media thickness, cardiovascular risk factors and albuminuria in a remote Australian Aboriginal community.

Atherosclerosis. 2004;177(2):423-31.

32. Rosenquist KJ, Massaro JM, Pencina KM, D'Agostino RB, Beiser A, O'Connor GT, et al. Neck circumference, carotid wall intima-media thickness, and incident stroke. Diabetes Care. 2013;36(9):e153-e4.

33. Spence JD. Determinants of carotid plaque burden. Atherosclerosis. 2016;255:122-3.

34. Johnsen SH, Mathiesen EB, Joakimsen O, Stensland E, Wilsgaard T, Lochen ML, et al. Carotid atherosclerosis is a stronger predictor of myocardial infarction in women than in men: a 6-year follow-up study of 6226 persons: the Tromso Study. Stroke. 2007;38(11):2873-80.

35. Sillesen H, Muntendam P, Adourian A, Entrekin R, Garcia M, Falk E, et al. Carotid plaque burden as a measure of subclinical atherosclerosis: comparison with other tests for subclinical arterial disease in the High Risk Plaque Biolmage study. JACC Cardiovasc Imaging. 2012;5(7):681-9. 36. Lu Y, Hajifathalian K, Ezzati M, Woodward M, Rimm EB, Danaei G. Metabolic mediators of the effects of body-mass index, overweight, and obesity on coronary heart disease and stroke: a pooled analysis of 97 prospective cohorts with 1.8 million participants. Lancet. 2014;383(9921):97083. 
37. Ndumele CE, Matsushita K, Lazo M, Bello N, Blumenthal RS, Gerstenblith G, et al. Obesity and Subtypes of Incident Cardiovascular Disease. J Am Heart Assoc. 2016;5(8).

38. Despres JP. Body fat distribution and risk of cardiovascular disease: an update. Circulation. 2012;126(10):1301-13.

39. Shuster A, Patlas M, Pinthus JH, Mourtzakis M. The clinical importance of visceral adiposity: a critical review of methods for visceral adipose tissue analysis. Br J Radiol. 2012;85(1009):1-10.

40. Alexopoulos N, Katritsis D, Raggi P. Visceral adipose tissue as a source of inflammation and promoter of atherosclerosis. Atherosclerosis. 2014;233(1):104-12.

41. Onat A, Avcı GŞ, Barlan M, Uyarel H, Uzunlar B, Sansoy V. Measures of abdominal obesity assessed for visceral adiposity and relation to coronary risk. International journal of obesity. 2004;28(8):1018-25.

42. Pouliot MC, Despres JP, Lemieux S, Moorjani S, Bouchard C, Tremblay A, et al. Waist circumference and abdominal sagittal diameter: best simple anthropometric indexes of abdominal visceral adipose tissue accumulation and related cardiovascular risk in men and women. Am J Cardiol. 1994;73(7):460-8.

43. Yim JY, Kim D, Lim SH, Park MJ, Choi SH, Lee CH, et al. Sagittal abdominal diameter is a strong anthropometric measure of visceral adipose tissue in the Asian general population. Diabetes Care. 2010;33(12):2665-70.

44. Yusuf S, Hawken S, Ounpuu S, Bautista L, Franzosi MG, Commerford P, et al. Obesity and the risk of myocardial infarction in 27,000 participants from 52 countries: a case-control study. Lancet. 2005;366(9497):1640-9.

45. Dagenais GR, Yi Q, Mann JF, Bosch J, Pogue J, Yusuf S. Prognostic impact of body weight and abdominal obesity in women and men with cardiovascular disease. Am Heart J. 2005;149(1):54-60.

46. de Koning L, Merchant AT, Pogue J, Anand SS. Waist circumference and waist-to-hip ratio as predictors of cardiovascular events: meta-regression analysis of prospective studies. Eur Heart J. 2007;28(7):850-6.

47. Hutcheon JA, Chiolero A, Hanley JA. Random measurement error and regression dilution bias. Bmj. 2010;340:c2289.

48. Mannsverk J, Wilsgaard T, Mathiesen EB, Lochen ML, Rasmussen K, Thelle DS, et al. Trends in Modifiable Risk Factors Are Associated With Declining Incidence of Hospitalized and Nonhospitalized Acute Coronary Heart Disease in a Population. Circulation. 2016;133(1):74-81.

49. Hogberg D, Kragsterman B, Bjorck M, Tjarnstrom J, Wanhainen A. Carotid artery atherosclerosis among 65-year-old Swedish men - a population-based screening study. Eur J Vasc Endovasc Surg. 2014;48(1):5-10.

50. Touboul PJ, Hennerici MG, Meairs S, Adams H, Amarenco P, Bornstein N, et al. Mannheim carotid intima-media thickness and plaque consensus (2004-2006-2011). An update on behalf of the advisory board of the 3rd, 4th and 5th watching the risk symposia, at the 13th, 15th and 20th European Stroke Conferences, Mannheim, Germany, 2004, Brussels, Belgium, 2006, and Hamburg, Germany, 2011. Cerebrovasc Dis. 2012;34(4):290-6.

51. Barnett PA, Spence JD, Manuck SB, Jennings JR. Psychological stress and the progression of carotid artery disease. J Hypertens. 1997;15(1):49-55. 


\section{Highlights}

* All adiposity measures were associated with total plaque area

* Most of the associations between plaque burden and adiposity appeared to be partially mediated by traditional CVD risk factor

*Waist-to-hip ratio showed the largest effect size among four adiposity measures 
Table 1. Participant characteristics of study population. The Tromsø Study 2001-02

\begin{tabular}{|c|c|c|}
\hline & $\begin{array}{l}\text { Participants included in } \\
\text { the analysis* }(n=4906)\end{array}$ & $\begin{array}{l}\text { Participants included in } \\
\text { the analysis with plaque } \\
* *(\mathrm{n}=2906)\end{array}$ \\
\hline $\begin{array}{l}\text { Age (years) } \\
\text { median(IQR) }\end{array}$ & $66(60-72)$ & $68(63-74)$ \\
\hline Sex (\% of women) & $2722(55.5)$ & $1450(49.9)$ \\
\hline Current smoker (\%) & $1249(25.5)$ & $794(27.3)$ \\
\hline Ex-smoker $(\%)$ & $1999(40.8)$ & $1234(42.5)$ \\
\hline Education (year) & $9.9(3.6)$ & $9.4(3.3)$ \\
\hline SBP $(\mathrm{mmHg})$ & $143.0(21.6)$ & $147.3(21.5)$ \\
\hline \multicolumn{3}{|l|}{$\begin{array}{l}\text { Anthropometry } \\
\text { measures }\end{array}$} \\
\hline Height $(\mathrm{cm})$ & $167.4(9.3)$ & $167.3(9.5)$ \\
\hline Weight (kg) & $75.2(13.9)$ & $75.1(13.8)$ \\
\hline BMI $\left(\mathrm{kg} / \mathrm{m}^{2}\right)$ & $26.8(4.2)$ & $26.8(4.1)$ \\
\hline $\mathrm{WC}(\mathrm{cm})$ & $90.3(12.2)$ & $91.1(12.0)$ \\
\hline WHR & $0.89(0.09)$ & $0.90(0.09)$ \\
\hline WHtR & $0.54(0.07)$ & $0.55(0.07)$ \\
\hline \multicolumn{3}{|l|}{ Blood sample } \\
\hline $\begin{array}{l}\text { HDL cholesterol } \\
(\mathrm{mmol} / \mathrm{l}) \text { median }(\mathrm{IQR})\end{array}$ & $1.43(1.19-1.72)$ & $1.42(1.18-1.70)$ \\
\hline $\begin{array}{l}\text { LDL cholesterol } \\
(\mathrm{mmol} / \mathrm{l})\end{array}$ & $4.11(1.07)$ & $4.16(1.09)$ \\
\hline $\begin{array}{l}\text { Triglycerides (mmol/l) } \\
\text { median (IQR) }\end{array}$ & $1.34(0.96-1.90)$ & $1.39(1.00-1.94)$ \\
\hline $\mathrm{HbA} 1 \mathrm{C}(\%)$ & $5.50(0.80)$ & $5.58(0.83)$ \\
\hline \multicolumn{3}{|l|}{$\begin{array}{l}\text { Comorbidities (self- } \\
\text { report) }\end{array}$} \\
\hline Diabetes $(\%)$ & $222(4.6)$ & $152(5.4)$ \\
\hline $\begin{array}{l}\text { Myocardial infarction } \\
(\%)\end{array}$ & $378(7.9)$ & $311(11.0)$ \\
\hline Angina pectoris (\%) & $501(10.5)$ & $398(14.1)$ \\
\hline Stroke $(\%)$ & $191(4.0)$ & $148(5.2)$ \\
\hline \multicolumn{3}{|l|}{$\begin{array}{l}\text { Current medication } \\
\text { (self-report) }\end{array}$} \\
\hline $\begin{array}{l}\text { Anti hypertensive drug } \\
(\%)\end{array}$ & $1194(24.9)$ & 869 (31.7) \\
\hline $\begin{array}{l}\text { Lipid lowering drug } \\
(\%)\end{array}$ & $708(15.0)$ & $541(19.5)$ \\
\hline \multicolumn{3}{|l|}{ Carotid variable } \\
\hline plaque presence $(\%)$ & $2906(59.2 \%)$ & $2906(100 \%)$ \\
\hline \multicolumn{3}{|l|}{ the number of plaque } \\
\hline 1 & $1372(28.0)$ & $1372(47.2)$ \\
\hline 2 & $931(19.0)$ & $931(32.0)$ \\
\hline 3 & $427(8.7)$ & $427(14.7)$ \\
\hline 4 & $134(2.7)$ & $134(4.6)$ \\
\hline 5 & $36(0.7)$ & $36(1.2)$ \\
\hline 6 & $6(0.1)$ & $6(0.2)$ \\
\hline TPA $\left(\mathrm{mm}^{2}\right)$ & & $17.6(10.0-31.3)$ \\
\hline
\end{tabular}

Data are mean values with standard deviations for continuous variables except for age, triglycerides, HDL cholesterol, and TPA which is shown with median and interquartile range. BMI: body mass index, WC: waist circumference, WHR: waist-to-hip ratio, WHtR: waist-to-hight ratio, HDL: high-density lipoprotein, LDL: lowdensity lipoprotein, HbA1c: glycated haemoglobin, TPA: total plaque area *Participants are restricted to those with all main variables and non-missing TPA variable**Participants are restricted to those with all main variables and at least one plaque 
Table 2. The association between adiposity and TPA quartiles (crude). The Tromsø Study 200102.

\begin{tabular}{|l|l|l|l|l|l|}
\hline & $\begin{array}{l}\text { Total } \\
\text { number* }\end{array}$ & $\begin{array}{l}\text { BMI } \\
\left(\mathrm{kg} / \mathrm{m}^{2}\right)\end{array}$ & $\begin{array}{l}\text { WC } \\
(\mathrm{cm})\end{array}$ & WHR & WHtR \\
\hline $\begin{array}{l}\text { Persons without } \\
\text { plaques }\end{array}$ & 2000 & $26.8(4.3)$ & $89.0(12.5)$ & $0.87(0.09)$ & $0.53(0.07)$ \\
\hline Persons with plaques & & & & & \\
\hline TPA quartile 1 (lowest) & 727 & $26.7(4.2)$ & $89.3(11.9)$ & $0.88(0.09)$ & $0.54(0.07)$ \\
\hline TPA quartile 2 & 726 & $27.1(4.3)$ & $91.2(12.3)$ & $0.89(0.09)$ & $0.55(0.07)$ \\
\hline TPA quartile 3 & 727 & $26.6(3.9)$ & $90.8(11.7)$ & $0.90(0.09)$ & $0.54(0.07)$ \\
\hline TPA quartile 4 & 726 & $26.7(4.0)$ & $93.2(11.7)$ & $0.92(0.08)$ & $0.55(0.07)$ \\
\hline
\end{tabular}

Data are mean values with standard deviations. BMI: body mass index, WC: waist circumference, WHR: waistto-hip ratio, WHtR: waist-to-hight ratio, TPA: total plaque area *Only the participants with all adiposity variables and covariates are used in this table 
Table 3. The association between sex-specific standardized adiposity scores and the presence of plaque (Yes/No) using logistic regression: this analysis is restricted to participants with non-missing presence of plaque variable and all variables in the model (n=4906). The Tromsø Study 200102.

\begin{tabular}{|c|c|c|c|c|c|c|}
\hline & Model 1 OR (95\%CI) & p-value & Model 2 OR $(95 \% \mathrm{CI})$ & p-value & Model 3 OR $(95 \%$ CI $)$ & p-value \\
\hline st BMI & $0.98(0.92,1.04)$ & 0.45 & $1.03(0.96,1.09)$ & 0.45 & $0.95(0.88,1.01)$ & 0.11 \\
\hline st WC & $0.98(0.92,1.05)$ & 0.58 & $1.01(0.95,1.08)$ & 0.79 & $0.92(0.86,0.99)$ & 0.03 \\
\hline st WHR & $1.08(1.01,1.15)$ & 0.02 & $1.07(1.01,1.15)$ & 0.03 & $1.01(0.94,1.08)$ & 0.87 \\
\hline st WHtR & $1.02(0.96,1.08)$ & 0.57 & $1.04(0.98,1.11)$ & 0.21 & $0.96(0.90,1.03)$ & 0.28 \\
\hline
\end{tabular}

St BMI:standardized body mass index, st WC: standardized waist circumference, st WHR: standardized waist-to-hip ration, st WHtR: standardized waist-to-height ratio, OR: odds ratio, 95\% CI: 95\% confidence interval, SD: standard deviation, Model 1: adjusted for age and sex, Model 2: adjust for variables in Model 1 plus other confounders (smoking and education), Model 3: adjusted for variables in Model 2 and mediators (systolic blood pressure, HDL cholesterol, LDL-cholesterol, glycated hemoglobin)

Table 4. The association between sex-specific standardized adiposity scores and log-transformed TPA using linear regression: this analysis is restricted to participants with plaque and all variables in the model $(\mathrm{n}=2906)$. The Tromsø Study 2001-02.

\begin{tabular}{|l|l|l|l|l|l|}
\hline & Model $1 \beta(95 \% \mathrm{CI})$ & $\mathrm{p}$-value & Model $2 \beta(95 \% \mathrm{CI})$ & $\mathrm{p}$-value & Model 3 $\beta(95 \% \mathrm{CI})$ \\
\hline st BMI & $0.012(-0.015,0.039)$ & 0.38 & $0.032(0.004,0.059)$ & 0.02 & $0.002(-0.026,0.031)$ \\
\hline st WC & $0.031(0.005,0.058)$ & 0.02 & $0.042(0.015,0.068)$ & 0.002 & $0.012(-0.017,0.040)$ \\
\hline st WHR & $0.056(0.029,0.083)$ & $<0.001$ & $0.055(0.028,0.081)$ & $<0.001$ & $0.030(0.002,0.058)$ \\
\hline st WHtR & $0.038(0.011,0.065)$ & 0.005 & $0.046(0.019,0.073)$ & 0.001 & 0.04 \\
\hline
\end{tabular}

St BMI: standardized body mass index, st WC: standardized waist circumference, st WHR: standardized waist-to-hip ratio, st WHtR: standardized waist-to-height ratio, $\beta$ : regression coefficient, 95\% CI: 95\% confidence interval, SD: standard deviation, Model 1: adjusted for age and sex, Model 2: adjust for variables in Model 1 plus other confounders (smoking and education), Model 3: adjusted for variables in Model 2 and mediators (systolic blood pressure, HDL cholesterol, LDL-cholesterol, glycated hemoglobin) 